\title{
Perceptions of Nursing Students Face Their Trainee Supervisors (Case of the University Clinics of Lubumbashi)
}

\author{
Kaki Khang Mariette1, Khang Imvar Esther², Mudisu Kayinga Loriot1, Mindje Kolomba3, \\ Kabamba Nzaji Michel4
}

${ }^{1}$ Nursing Section, Department of Education and Administration in Nursing, Higher Institute of Medical Technology,

Lubumbashi, Democratic Republic of Congo

${ }^{2}$ Section of Biomedical Management and Technics, Department of Medical Biology, Higher Institute of Medical

Technology of Lubumbashi, Lubumbashi, Democratic Republic of Congo

${ }^{3}$ General Hospital of Reference, Kamina, Democratic Republic of Congo

${ }^{4}$ Faculty of Medicine, Department of Public Health, University of Kamina, Kamina, Democratic Republic of Congo

Email: michelnzaji@yahoo.fr

How to cite this paper: Mariette, K.K., Esther, K.I., Loriot, M.K., Kolomba, M. and Michel, K.N. (2016) Perceptions of Nursing Students Face Their Trainee Supervisors (Case of the University Clinics of Lubumbashi). Open Access Library Journal, 3: e3216.

http://dx.doi.org/10.4236/oalib.1103216

Received: November 9, 2016

Accepted: December 6, 2016

Published: December 9, 2016

Copyright $\odot 2016$ by authors and Open Access Library Inc.

This work is licensed under the Creative Commons Attribution International License (CC BY 4.0)

http://creativecommons.org/licenses/by/4.0/

\section{(c) (i) Open Access}

\begin{abstract}
Teaching aims to introduce the learner to the realities of social and professional life. In the context of vocational education, these learning activities are confined to two interacting poles, namely learning in a school situation (simulation) and that in a clinical situation, that is to say next to the patient. The general objective of this study was to raise the awareness of nursing supervisors to improve the quality of the supervision they offer to trainee students in their professional circles in order to overcome this challenge. We used a prospective, cross-sectional descriptive study conducted at the university clinics in Lubumbashi. The study found that $54 \%$ of the trainees were female, $46 \%$ male; $47.3 \%$ were between 21 and 25 years old and $24.3 \%$ between 31 and 35 years of age; The attitude of the Trainees towards the trainee supervisors was distrustful in 36\% of the cases and Positive in 27\%; Indifferent in 26\% of cases. In relation to the quality of the supervision, $38 \%$ of the students found this to be of poor quality and $39 \%$ said that the quality was good. The supervision of students seems to be a real challenge for all the care management of an institution and for the educational institution that sent these trainees. The commitment of all is necessary to carry out this mission of supervision of internstudents.
\end{abstract}

\section{Subject Areas}

Nursing, Public Health 


\section{Keywords}

Perception, Nurses, Coaching, Internship

\section{Introduction}

Teaching aims to introduce the learner to the realities of social and professional life. In the context of vocational education, these learning activities are confined to two interacting poles, namely learning in a school situation (simulation) and that in a clinical situation, that is to say next to the patient.

In fact, a certain number of minimum skills must be covered by the learner at the end of his training. This is a comprehensive training aim using the various abilities including knowledge, expertise, know-how and know-how to become. It is the foundation of professional skills developed not by learners, but by professionals. They come from the combination of further training and work experience.

Renaud considers that monitoring a learner is not only about helping him to progress technically, but also about thinking about care and how to provide it. We are of the opinion that the theories learned in class situations must be linked to professional or field realities.

Jean Georges and al are of the opinion that the internship constitutes for the learner a place of practice, confrontation with professional reality and taking active responsibilities. This leads the learner to acquire professional know-how.

For a very long time, health establishments have organized and supported the supervision and training of health professionals. Clinical teaching is an integral part of the training: internships are an indispensable activity for the learning and professionalization of people destined for the health professions [1].

When nursing students are trained in healthcare establishments, they are entrusted to nursing staff that, as tutors, have the task of accompanying them and evaluating them as part of their professional training [2].

To do this, the tutor "uses the evaluation tools and in particular the portfolio in order to formalize the acquisition of skills and the performance of the acts and activities (of his trainee). It organizes intermediate assessments during the course". In other words, the tutor seems to have the main tasks of accompanying and evaluating the trainee. On the one hand, it is a question of giving him help and support on the ground; on the other hand, to pass judgment on him with the professionals of proximity [3].

An internship can be beneficial to the student only if the student is well supervised by a person with expertise in the nursing profession. Indeed, novice, the trainee needs to be guided and for this the nurse must take the time to detail and explain all his gestures, to give answers to the questions of the student, to teach him Practice tricks, etc.

To prepare nursing students to practice their future profession, it seems logical that they be supervised by experienced staff as expressed by Petiot: "The caregiver is also chosen according to the expertise he possesses; in fact novice tutors with little expertise 
in a service are not then solicited to supervise the students" [4].

While organizational speeches and attempts at internships try to bring together the stakes and opinions of the involved actors, there are often attitudes of indifference, avoidance strategies: exchanges where each type of "Actor refers the responsibility for unsatisfactory results or dysfunction on the other two. The students refer to dysfunctions in the reception, the supervision on training course, a lack of availability, motivation, an overestimated requirement in the expectations of professionals against learners" [5].

In short, the nurse must be a professional model because, due to lack of experience, the trainee will get an idea of this trade mainly through what he will see during his internship. So, hosting a nursing student internship requires a lot of patience and time for any nurse. The nurse supervisor who is supposed to supervise must possess sufficient knowledge on the pedagogy of practical supervision and especially in his field of training as well as information. Nevertheless, on the ground many supervisors do not master first the subjects of their field of study and the practice or the experience of their profession. Other problems are, such as, the irregularity of the supervisors in clinical settings, the lack of trust in the students by the nurses, the refusal to collaborate with the students, and the lack of motivation in the clinical circles. Thus, countless problems mentioned above in the choice of this research topic are observed during the supervision of the trainees. Thus, countless problems mentioned above in the choice of this research topic are observed during the supervision of the trainees [6].

In the light of all these concerns raised above, the central question of this research is formulated as follows: What would be the perception of internstudents face to their trainee supervisors?

The general objective of this study was to raise the awareness of nursing supervisors to improve the quality of the supervision they offer to trainee students in their professional circles in order to overcome this challenge. It has set itself the specific objectives of determining the socio-demographic characteristics of trainee students as well as the assessment of the quality of supervision by the latter.

\section{Methods}

It was a prospective, cross-sectional descriptive study. The study population consisted of students who were on probation at the university clinics in Lubumbashi. Our sampling was exhaustive. We used the questionnaire to collect the data in this study. The data were processed and analyzed using the Epi-Info 7 software. Our study was carried out for two months, from March to June 2014. Participants in this study were informed about the results of this research. Informed, they did not hesitate to contribute to its progress. The confidentiality of the speakers or participants was guaranteed.

\section{Results}

It appears from Table 1 that $54 \%$ of the trainees were females, $46 \%$ males; $47.3 \%$ were between 21 and 25 years old and $24.3 \%$ between 31 and 35 years. 22 trainees (30\%) were 
Table 1. General characteristics of trainee students surveyed.

\begin{tabular}{ccc}
\hline General characteristics of students & Number $\mathbf{n}=\mathbf{7 4}$ & Percentage \\
\hline Sex & 40 & $54 \%$ \\
Female & 34 & $46 \%$ \\
Male & & \\
age range & 35 & $47.3 \%$ \\
$21-25$ & 18 & $24.3 \%$ \\
$26-30$ & 12 & $16.2 \%$ \\
$31-35$ & 9 & $12.2 \%$ \\
36 - 40 & & \\
Services & 21 & $28 \%$ \\
Internal Medicine & 19 & $26 \%$ \\
Surgery & 22 & $30 \%$ \\
Pediatrics & 12 & $16 \%$ \\
\hline Obstetrics and Gynecology & & \\
\hline
\end{tabular}

Table 2. Perception of students face to the availability of objectives, care materials, assistance and correction of errors during the performance of care.

\begin{tabular}{|c|c|c|}
\hline & Headcount $(N=74)$ & Percentage \\
\hline \multicolumn{3}{|c|}{ Availability of internship objectives } \\
\hline Yes & 56 & $76 \%$ \\
\hline No & 18 & $24 \%$ \\
\hline \multicolumn{3}{|c|}{ clear definition of training objectives } \\
\hline Yes & 59 & $80 \%$ \\
\hline No & 15 & $20 \%$ \\
\hline \multicolumn{3}{|c|}{ Availability of health care materials } \\
\hline Yes & 35 & $47 \%$ \\
\hline No & 39 & $53 \%$ \\
\hline \multicolumn{3}{|c|}{ Materials sufficient care } \\
\hline Yes & 45 & $60 \%$ \\
\hline No & 29 & $40 \%$ \\
\hline \multicolumn{3}{|c|}{ Correction of errors } \\
\hline Yes & 31 & $42 \%$ \\
\hline No & 43 & $58 \%$ \\
\hline \multicolumn{3}{|c|}{ easy Exchange } \\
\hline Yes & 26 & $35 \%$ \\
\hline No & 48 & $65 \%$ \\
\hline \multicolumn{3}{|c|}{ Assistance while performing care } \\
\hline Yes & 36 & $49 \%$ \\
\hline No & 38 & $51 \%$ \\
\hline
\end{tabular}


Table 3. Attitude and appreciation of the quality of supervision by trainee students.

\begin{tabular}{ccc}
\hline & Effective $(\mathbf{N}=74)$ & Percentage \\
\hline Attitude & & \\
Positive & 20 & $27 \%$ \\
Mistress & 27 & $36 \%$ \\
Indifferent & 19 & $26 \%$ \\
No opinion & 8 & $11 \%$ \\
Appreciation of the quality of supervision & & \\
Best & 17 & $23 \%$ \\
Quite good & 29 & $39 \%$ \\
Bad & 28 & $38 \%$ \\
\hline
\end{tabular}

interviewed in the pediatric department, $21(28 \%)$ in the internal medicine department and $12(16 \%)$ were interviewed in the gynecological obstetrics department.

It emerges from Table 2 and Table 3 that the attitude of trainees towards the trainee supervisors is mistrustful in $36 \%$ of the cases and Positive in 27\%; Indifferent in $26 \%$ of cases. According to the quality of the supervision, $38 \%$ of the students find it of poor quality and $39 \%$ say that it is quite good.

\section{Discussion}

Nearly $77 \%$ of intern students find that the quality of coaching is quite good or bad. These results are similar with those of the survey of interruptions and drop-outs in nursing education in Ile-de-France [7]. According to this author, students who stopped their schooling mainly put forward difficulties encountered on the field of training: shift, reality/theory, unsatisfactory conditions of supervision, difficulties to carry out quality work ... They also bring up Psychosocial difficulties related to work (stress, emotional difficulties ...), unmet professional expectations and personal difficulties (finances ...). This attitude of the nursing trainees may be explained in this study by the fact that the trainees do not play their part. The latter must know that tutoring is a necessity for the professional development, the attractiveness of the profession and the pursuit of the exercise. Tutoring, on the other hand, facilitates intergenerational cohabitation. The informal exchanges and the "orality" they imply are irreplaceable to develop a technical companion, able to deal with precise and psychological difficulties.

It should be noted that in other countries there are texts that legislate the profession including the ability to transfer knowledge. But this ability is learned a lot by following a referent caregiver, stable throughout an internship, and observing his methods to transfer his practical and behavioral knowledge. But this tutor must first be trained in adult training methods that differ from classical school methods.

This study showed a difficulty of exchange between supervisor and trainees and that almost $60 \%$ of the latter recognized that they are not corrected in case of error and are not assisted during the execution of the care. These results can be explained by the fact 
that the supervisor ignores his role as tutor. The etymology of this term gives us a role in protecting others and showing kindness towards those who need help. The tutorial relationship thus seems to call upon two dimensions which, combined, give shape to what Moust calls "cognitive congruence" [8]. A union which is not very evident in the case of two quasi-opposite dimensions. The first, called "social congruence", marks a certain proximity between the tutor and his tutored, thus the attention given by the first to the latter. The second, the "expertise", on the contrary reveals a distance between the one and the other because it is, at least initially, only on the side of the tutor. Here are the conditions that allow the tutor to be sensitive to the problems encountered by his tutored, to listen to him, and finally to be able to help him. This is, in our opinion, the profile of the ideal tutor in the school field and certainly elsewhere. It is to be found in the following alchemy: "The association of academic skills (expertise) and personal qualities (social congruence). This learned mixture gives the person a highly appreciated quality: cognitive congruence" [2].

Barnier, does not think so because it is difficult to "find good professionals in a position of scalability who are able to transmit know-how and accompany the process of building and acquiring skills of the learner. And who are also open to the other, capable of listening, knowing how to communicate, and motivated to accompany the other". Any more reason to worry about a possible shortage of tutors in the years to come? It's possible. Let us bet that the culture of the gift that animates the hospital since its origins is still sufficiently present so that it may not be so, this in order that there may be permanently a pool of tutors ready to accompany nursing students In their training curriculum [9].

A problem found, among others, in the Democratic Republic of Congo, where the administration which supervises the training of nursing personals advocates a constructivist approach of learning, theoretical/practical links, the development of a reflexive approach among trainees [6]. In fact, in the field tutors do what they can, being delivered to themselves and unprepared for the accompanying methods corresponding to these instructions.

\section{Conclusions}

This study permitted to found that $54 \%$ of the trainees were female, $46 \%$ male; $47.3 \%$ were between 21 and 25 years old and $24.3 \%$ between 31 and 35 years of age; The attitude of the trainees towards the trainees supervisors was distrustful in $36 \%$ of cases and Positive in 27\%; Indifferent in $26 \%$ of the cases. In relation to the quality of the supervision, $38 \%$ of the students found this to be of poor quality and $39 \%$ said that it was good enough.

The supervision of students seems to be a real challenge for all the care management of an institution and for the educational institution that sent these trainees. Indeed, the coherence between the theoretical teaching practiced and the practice in the sectors of care must contribute to the fluidity of the course of the student, so that this one benefits from an optimal formation. Moreover, the quality of the training of future professionals will depend on the skills of these professionals. The commitment of all is necessary to 
carry out this mission of supervision of intern students. In our opinion, student coaching must be part of a comprehensive human resources management policy that takes into consideration the conditions for the development of nurses' competencies.

\section{References}

[1] Jovic, L., Goldszmidt, D., Monguillon, D., Goldszmidt, D. and Monguillon, D. (2010) Supervision of Students in Training, Education and Research: Evaluation and Optimization of Activities Carried Out by Paramedics. Research in Nursing, 101, 81.

[2] Baudrit, A. (2012) Being Now Guardian of Nursing Students: A Complex and Perennial Mission. Nursing Research, 111, 6.

[3] Lamasse, V. (2010) The Coaching Internship Nursing Students: A Challenge for the Department of Health. School for Advanced Studies in Public Health, Rennes, 39.

[4] Petiot, B. (2010) Tutorer of Nursing Students: A Gift for a Cons-Donation? TER of Master 1 of Sciences of the Education. Université Victor Segalen Bordeaux 2, 55.

[5] Jouanchin, N. (2010) The Application Placement in Nursing Education, Professional Performances and Involving Actors: Future Nurses, Trainers and Managers/Internship Tutors. Research in Nursing, 101, 42.

[6] Kba Tambwe Kabamba, J. and Akumbakinayo Muinida, D. (2005) The Perception of Nurses in the Supervision of Trainees in Care Institutions on the Transfer. Interdisciplinary Centre for the Development of Continuing Education, Kinshasa.

[7] Lamaurt, F., Estryn-Behar, Le Moël, R., Chrétien, T. and Mathieu, B. (2011) Survey of Health Care Experiences and Behaviors of Nursing Students. Nursing Research, 105, 44.

[8] Moust, J.H.C. (1993) On the Role of Tutors in Problem-Based Learning: Contrasting Student-Guided with Staff-Guided Tutorials. University of Maastricht, Maastricht.

[9] Barnier, G. (2001) Mentoring in Education and Training. The Harmattan.

\section{Submit or recommend next manuscript to OALib Journal and we will provide best service for you:}

- Publication frequency: Monthly

- 9 subject areas of science, technology and medicine

- Fair and rigorous peer-review system

- Fast publication process

- Article promotion in various social networking sites (LinkedIn, Facebook, Twitter, etc.)

- Maximum dissemination of your research work

Submit Your Paper Online: Click Here to Submit

Or Contact service@oalib.com 